\title{
PRODUCTS OF GEODESIC GRAPHS AND THE GEODETIC NUMBER OF PRODUCTS
}

\author{
Jake A. SolofF ${ }^{1}$, Rommy A. MÁrquez ${ }^{2}$ \\ AND \\ LOUIS M. FRIEDLER ${ }^{2}$ \\ ${ }^{1}$ Department of Mathematics \\ Brown University \\ Providence, RI 02912 USA \\ ${ }^{2}$ Department of Computer Science and Mathematics \\ Arcadia University \\ Glenside, PA 19038 USA \\ e-mail: friedler@arcadia.edu
}

\begin{abstract}
Given a connected graph and a vertex $x \in V(G)$, the geodesic graph $P_{x}(G)$ has the same vertex set as $G$ with edges $u v$ iff either $v$ is on an $x-u$ geodesic path or $u$ is on an $x-v$ geodesic path. A characterization is given of those graphs all of whose geodesic graphs are complete bipartite. It is also shown that the geodetic number of the Cartesian product of $K_{m, n}$ with itself, where $m, n \geq 4$, is equal to the minimum of $m, n$ and eight.
\end{abstract}

Keywords: geodesic graph, geodetic number, Cartesian products.

2010 Mathematics Subject Classification: 05C12.

\section{REFERENCES}

[1] A.P. Santhakumaran and P. Titus, Geodesic graphs, Ars Combin. 99 (2011) 75-82.

[2] W. Imrich and S. Klavžar, Product Graphs: Structure and Recognition (Wiley, New York, 2000).

[3] B. Brešar, M. Kovše and A. Tepeh Horvat, Geodetic sets in graphs in: M. Dehmer (Eds.), Structural Analysis of Complex Networks, Springer Science+Business Media, LLC, New York (2011) 197-218. doi:10.1007/978-0-8176-4789-6_8 
[4] B. Brešar, S. Klavžar and A. Tepeh Horvat, On the geodetic number and related metric sets in Cartesian product graphs, Discrete Math. 308 (2008) 5555-5561. doi:10.1016/j.disc.2007.10.007

[5] F. Harary, E. Loukakis and C. Tsouros, The geodetic number of a graph, Math. Comput. Modelling 17 (1993) 89-95. doi:10.1016/0895-7177(93)90259-2

[6] G. Chartrand, F. Harary and P. Zhang, On the geodetic number of a graph, Networks 39 (2002) 1-6. doi: $10.1002 /$ net.10007

[7] J. Cáceres, C. Hernando, M. Mora, I.M. Pelayo and M.L. Puertas, On the geodetic and the hull numbers in strong product graphs, Comput. Math. Appl. 60 (2010) $3020-3031$.

doi:10.1016/j.camwa.2010.10.001

[8] T. Jiang, I. Pelayo and D. Pritikin, Geodesic convexity and Cartesian products in graphs, manuscript (2004).

[9] Y. Ye, C. Lu and Q. Liu, The geodetic numbers of Cartesian products of graphs, Math. Appl. 20 (2007) 158-163.

Received 27 August 2012

Revised 11 September 2013

Accepted 13 January 2014 